\title{
Electrochemical and Corrosion Properties of Aluminum Brass in Artificial Seawater
}

\author{
Hong JU *, Can SUN, Xia LI, Yunfei LIU, Jiejing CHEN, Li DING \\ College of Mechanical and Electronic Engineering, China University of Petroleum, Qingdao 266580, P.R. China \\ crossref http://dx.doi.org/10.5755/j01.ms.23.4.17170
}

Received 30 November 2016; accepted 05 March 2017

\begin{abstract}
The corrosion behavior and mechanism of aluminum brass (HAl77-2) in artificial seawater were investigated using electrochemical measurement, Scanning Electron Microscope (SEM) and Energy Dispersive X-ray spectroscopy (EDX) analysis. The electrochemical results revealed that the corrosion of HAl77-2 in the desalination artificial seawater depended on chloride ion concentrations, displaying a maximum with a chloride ion concentration of $2.3 \mathrm{wt}$. $\%$. Corrosion rate of HAl77-2 initial increased and subsequently decreased with the increasing of chloride ion concentration. Moreover, corrosion of HAl77-2 becomes more severe when temperature rises. The above results obtained by electrochemical impedance spectroscopy and potentiodynamic polarization tests were in a good agreement. The results of SEM and EDX methods showed selective localized corrosion appeared remarkably on the surface of HAl77-2.

Keyword: desalination, corrosion, electrochemical measurement, SEM, chloride ion.
\end{abstract}

\section{INTRODUCTION}

Naturally available fresh water reserves are not capable of meeting the fresh water demands because of water scarcity and pollution [1,2]. Luckily, desalination technology was developed and proven an effective way to solve this problem $[3,4]$. Desalination is widely adopted in Asia, Africa, Arab countries, Europe, Middle East, America, and Australia to meet their fresh water and process water demands [3,4]. The three most commonly applied desalination technologies are: Multi-stage Flash (MSF), Reverse Osmosis (RO) and Multi-Effect Distillation (MED) [5-11]. Meanwhile, aluminum brass is widely used to heat exchanger tubing, evaporator shells, tube plates, fabricate piping, water boxes, etc. in these desalination plants. Moreover, the evaporators for MSF and MED technologies are mainly constructed by aluminum brass and require a long-term operation under the environment of seawater desalination. Especially, key metal parts in distillation plant are susceptible to corrosion induced by the aggressive chloride concentration [12]. Therefore, it has significant value for the protection of desalination plant to investigate the corrosion behavior and mechanism of key aluminum brass parts in desalination environment.

In this work, the electrochemical behaviors and mechanism of the aluminum brass corrosion in the desalination environments were investigated by several conventional electrochemical techniques [13-17], including open circuit potential (OCP), potentiodynamic polarization, and Electrochemical Impedance Spectroscopy (EIS). Two affected corrosion factors, chloride ion concentration and temperature, which have an obvious influence on the corrosion behavior of aluminum brass in desalination environment, were discussed in detail. SEM and EDX were also employed to analyze the corrosion morphology of the HAl77-2 surface.

\section{EXPERIMENT}

\subsection{Specimen preparation}

The chemical compositions of aluminum brass (HAl772 ) are listed in Table 1. The working electrode specimens were regular arranged as a $10 \mathrm{~mm} \times 10 \mathrm{~mm} \times 10 \mathrm{~mm}$ matrix, and embedded in polyester excluding its underneath surface with a surface area of $1 \mathrm{~cm}^{2}$.

Table 1. Composition of HAl77-2 (wt.\%)

\begin{tabular}{|c|c|c|c|c|c|c|}
\hline Composition & $\mathrm{Cu}$ & $\mathrm{Al}$ & $\mathrm{Fe}$ & $\mathrm{Pb}$ & $\mathrm{As}$ & $\mathrm{Zn}$ \\
\hline wt. $\%$ & $76.0 \sim 79.0$ & $1.8 \sim 2.5$ & 0.06 & 0.07 & $0.02 \sim 0.06$ & Remaining \\
\hline
\end{tabular}

Table 2. Chloride formulation compositions and conductivity of artificial seawater with different chloride ion concentrations

\begin{tabular}{|c|c|c|c|c|c|}
\hline Cl, wt.\% Composition, $\mathrm{g} / \mathrm{L}$ & $\mathrm{NaCl}$ & $\mathrm{MgCl}_{2} \cdot 6 \mathrm{H}_{2} \mathrm{O}$ & $\mathrm{CaCl}_{2}$ & $\mathrm{pH}$ & $\mathrm{Conductivity,} \mathrm{mS} / \mathrm{cm}$ \\
\hline 1.5 & 19.46 & 8.80 & 0.92 & 8.05 & 47.1 \\
\hline 1.9 & 24.53 & 11.11 & 1.16 & 8.07 & 57.6 \\
\hline 2.3 & 29.98 & 13.52 & 1.42 & 7.73 & 67.3 \\
\hline 2.7 & 35.26 & 16.03 & 1.67 & 7.60 & 76.5 \\
\hline
\end{tabular}

${ }^{1}$ Corresponding author: Tel.: +86-187-24733900; fax: 0532-86983300.

E-mail address: juhong@upc.edu.cn (H. Ju) 
The surface of working electrodes mechanically abraded prior to use with different emery papers from 500 to 1200. Then, the working specimen was degreased with acetone, and rinsed with distilled water. Finally, the working electrodes were stored in a desiccator until use.

\subsection{Experimental condition}

According to the actual environmental conditions of the seawater desalination evaporator, experiments were carried out in artificial seawater with different concentrations of $\mathrm{Cl}^{-}$ (wt.\%). The artificial seawater was prepared by ultra-pure water and A.R. reagents including $\mathrm{NaCl}, \mathrm{MgCl}_{2}, \mathrm{CaCl}_{2}$, etc., in accordance with the national standard (GB8650-88), and the concentrations of $\mathrm{Cl}^{-}$(wt.\%) in the artificial seawater were $1.5 \%, 1.9 \%, 2.3 \%$, and $2.7 \%$ respectively.

The compositions, $\mathrm{pH}$ and conductivity of artificial seawater are shown in Table 2. According to the temperature range in the MSF and MED desalination evaporator, four temperatures of the experiment condition were $298 \mathrm{~K}$, $313 \mathrm{~K}, 328 \mathrm{~K}$, and $343 \mathrm{~K}$, respectively.

\subsection{Electrochemical measurements}

All the electrochemical measurements were carried out with a conventional three-electrode cell system, consisting of a saturated calomel electrode with Luggin capillary (SCE, reference electrode), a platinum sheet $\left(2 \mathrm{~cm}^{2}\right.$ area) counter electrode and a working electrode with an exposed area of 1 $\mathrm{cm}^{2}$. All potentials were given according to this reference electrode $\left(\mathrm{E}^{\circ}=0.241 \mathrm{~V} v s\right.$. $\left.\mathrm{SHE}\right)$.

The Solartron $1287+1255 \mathrm{~B}$ electrochemical workstation instrument was used with a Modulab software controller to measure the electrochemical behavior of the HAl77-2. Electrochemical measurements, including Opencircuit potential (OCP), electrochemical impedance spectroscopy (EIS), and potentiodynamic polarization test, were performed in the artificial seawater with different concentrations of $\mathrm{Cl}$. After the OCP value stabilized, the impedance measurement was performed firstly, and then was the potentiodynamic polarization test. EIS measurement was carried out at open circuit potential in the $100 \mathrm{kHz}$ to $10 \mathrm{MHz}$ frequency range, with a $10 \mathrm{mV}$ signal amplitude perturbation.

The potentiodynamic polarization curve was obtained by scanning the working electrode from $-250 \mathrm{mV}$ to $250 \mathrm{mV}$ versus OCP value with the rate of $0.1667 \mathrm{mV} / \mathrm{s}$. The corrosion rates (corrosion current densities) were analyzed and fitted from the polarization curves by linear extrapolation of the anodic and cathodic arms of the Tafel plots as well as the corrosion potential $\left(E_{c o r r}\right)$.

\subsection{SEM and EDX analysis}

The surface morphology analysis of HAl77-2 specimens after immersion in artificial seawater with concentrations of $\mathrm{Cl}^{-}$as $1.9 \mathrm{wt}$ \% for 30 days was performed on scanning electronic microscope (FEI Quanta200 ESEM), equipped with energy dispersive X-ray spectroscopy (EDX) detectors. The accelerating voltage was $25 \mathrm{kV}$.

\section{RESULTS AND DISCUSSION}

\subsection{Effect of $\mathrm{Cl}^{-}$concentration on corrosion behavior of HAl77-2}

Effect of $\mathrm{Cl}^{-}$concentration on corrosion behavior of HAl77-2 was investigated using electrochemical experiments in the artificial seawater at $313 \mathrm{~K}$. The OCP values of HAl77-2 in artificial seawater with different concentrations of $\mathrm{Cl}^{-}$are presented in Table 3. From the table we can find that, when concentration of $\mathrm{Cl}^{-}$was below 2.3 wt.\%, the OCP values of HAl77-2 had an electronegative direction shift with the concentration of $\mathrm{Cl}^{-}$ increasing. However, and then, when the concentration of $\mathrm{Cl}^{-}$was higher than $2.3 \mathrm{wt} . \%$, the OCP value raised slightly with concentration of $\mathrm{Cl}^{-}$increasing, indicating that corrosion tendency of HAl77-2 increased with the concentration of $\mathrm{Cl}^{-}$increasing, and reached the extreme when the concentration of $\mathrm{Cl}^{-}$was 2.3 wt.\%.

The potentiodynamic polarization curves of HAl77-2 in artificial seawater with different concentrations of $\mathrm{Cl}^{-}$are shown in Fig. 1. As shown in the figure, passivation behavior occurred in the anode process of polarization curves. And it also was obviously revealed from the figure that, concentration polarization phenomenon appeared in the cathode process of polarization curves, because the diffusion of dissolved oxygen was the main controlling step of corrosion rate for cathodic process in artificial seawater.

Parameters such as anodic Tafel slope $\left(b_{a}\right)$, cathodic Tafel slope $\left(b_{c}\right)$, corrosion potential $\left(E_{c o r r}\right)$, and corrosion current density $\left(i_{c o r r}\right)$ obtained from the potentiodynamic polarization curves of HAl77-2 in artificial seawater with different concentrations of $\mathrm{Cl}^{-}$are listed in Table 4. It is observed from the table that the chloride ion concentration affected both cathodic as well as the anodic reactions but cathodic reactions are more affected than anodic reactions, as the change in values $b_{c}$ is more. It was easily to found the corrosion potential $\left(E_{\text {corr }}\right)$ of HAl77-2 dropped first and then enhanced with the concentration of $\mathrm{Cl}^{-}$increasing. When the concentration of $\mathrm{Cl}^{-}$was $2.3 \mathrm{wt}$.\%, the corrosion potential of HAl77-2 performed the most negative value. Meanwhile, its corresponding corrosion current density $\left(i_{\text {corr }}\right)$ of HAl77-2 initial increased and subsequently decreased. The maximum corrosion current value of Hal77-2HAl77-2 appeared when the concentration of $\mathrm{Cl}^{-}$reached $2.3 \mathrm{wt}$. \%. At this time, the anode corrosion behaved the most serious. In summary, the corrosion of anode initially accelerated by increasing concentration of $\mathrm{Cl}^{-}$in artificial seawater. However, when the concentration of $\mathrm{Cl}^{-}$was higher than $2.3 \mathrm{wt} . \%$, the corrosion rate of the anode started to decrease. This phenomenon was due to the combined effects of both chloride concentration and concentration of dissolved oxygen. Specifically, the solution conductivity increased with increasing concentration of $\mathrm{Cl}^{-}$, thereby enhancing the corrosion tendency associated to galvanic metal elements of HAl77-2, such as $\mathrm{Zn}, \mathrm{Al}, \mathrm{Cu}$, etc.. However, at high concentration of chloride ion, the dissolved oxygen concentration decreased and, as a result, the corrosion rate reduced by cathodic process of corrosion hindering. And the possible anodic Eq. 1 and cathodic Eq. 2 are as following:

$\mathrm{Zn} \rightarrow \mathrm{Zn}^{2+}+2 \mathrm{e} / \mathrm{Al} \rightarrow \mathrm{Al}^{3+}+3 \mathrm{e}$ 
$\mathrm{O}_{2}+2 \mathrm{H}_{2} \mathrm{O}+4 \mathrm{e} \rightarrow 4 \mathrm{OH}^{-}$

Table 3. The OCP values of HAl77-2 in artificial seawater with different concentrations of $\mathrm{Cl}^{-}$at $313 \mathrm{~K}$

\begin{tabular}{|c|c|c|c|c|}
\hline$C_{\mathrm{Cl}-}, \mathrm{wt} . \%$ & 1.5 & 1.9 & 2.3 & 2.7 \\
\hline$O C P, \mathrm{~V}$ & -0.234 & -0.239 & -0.265 & -0.263 \\
\hline
\end{tabular}

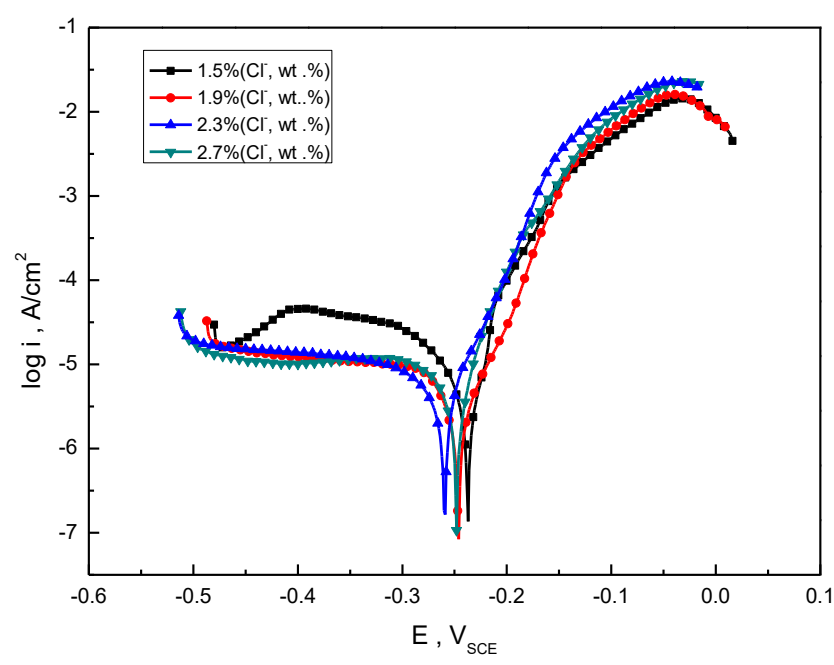

Fig. 1. Potentiodynamic polarization curves of HAl77-2 in artificial seawater with different concentrations of $\mathrm{Cl}^{-}$at $313 \mathrm{~K}$

Table 4. Parameters from potentiodynamic polarization curves for HAl77-2 in artificial seawater with different concentrations of $\mathrm{Cl}^{-}$at $313 \mathrm{~K}$

\begin{tabular}{|c|c|c|c|c|}
\hline$C_{\mathrm{Cl}-}, \mathrm{wt} . \%$ & $b_{a}, \mathrm{mV} \cdot \mathrm{sec}^{-1}$ & $b_{c}, \mathrm{mV} \cdot \mathrm{sec}^{-1}$ & $i_{\text {corr }}, \mathrm{A} \cdot \mathrm{cm}^{-2}$ & $E_{\text {corr },} \mathrm{V}$ \\
\hline 1.5 & 28.321 & -119.86 & $3.132 \times 10^{-6}$ & -0.235 \\
\hline 1.9 & 35.804 & -199.61 & $4.698 \times 10^{-6}$ & -0.239 \\
\hline 2.3 & 53.799 & -218.99 & $7.336 \times 10^{-6}$ & -0.273 \\
\hline 2.7 & 37.304 & -163.04 & $4.058 \times 10^{-6}$ & -0.253 \\
\hline
\end{tabular}

The impedance behavior of HAl77-2 in artificial seawater with different concentrations of $\mathrm{Cl}^{-}$is shown in Fig. 2.

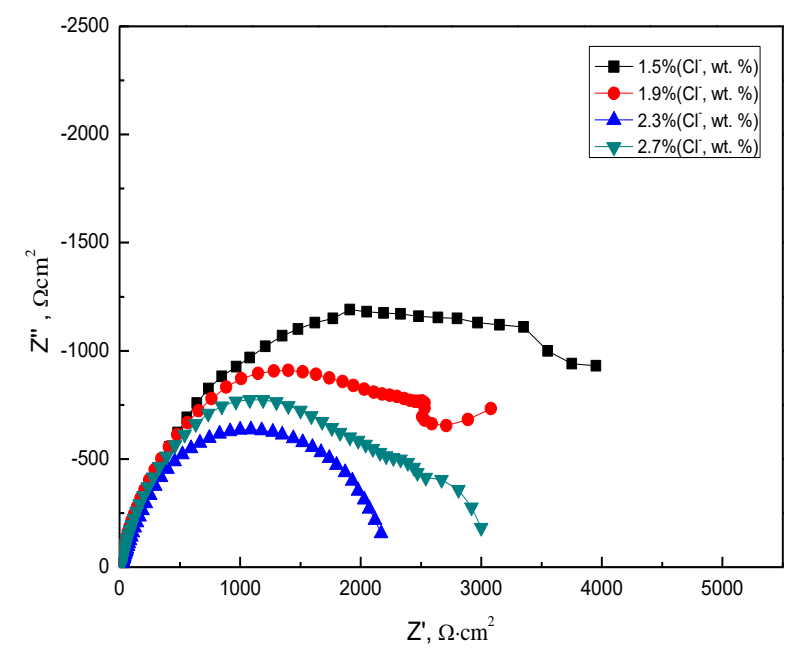

Fig. 2. EIS response of HAl77-2 in artificial seawater with different concentrations of $\mathrm{Cl}^{-}$at $313 \mathrm{~K}$
As shown in the figure, there was a capacitive loop at higher frequencies, and then appeared a second tail loop at the lower frequencies. The high frequencies loop related to the charge transfer from the ionic double layer capacitance, while the second tail loop attributed to the diffusion process of corrosion product or passivation film. Since the HAl77-2 was mainly composed of $\mathrm{Cu}, \mathrm{Al}$ and $\mathrm{Zn}$, the corrosion of the surface considered as a homogeneous corrosion, and $\mathrm{Zn}$ and $\mathrm{Al}$ dissolved at priority when metal surface exposed to the artificial seawater. The selected corrosion resulted in two loop characters in the impedance behavior. The ions diffused from the metal surface to the solution giving a second tail loop indicating diffusion resistance from the passivation film of $\mathrm{Al}$ and $\mathrm{Cu}$ at low frequencies in the electrochemical impedance spectroscopy of HAl77-2. Fig. 2 also showed that before the concentration of $\mathrm{Cl}^{-}$reached $2.3 \mathrm{wt} . \%$, the polarization resistance decreased with the concentration of $\mathrm{Cl}^{-}$increasing, which indicated an increase in the active surface area caused by concentration of $\mathrm{Cl}^{-}$increasing, and indicated the corrosion process became accelerated.

The equivalent circuit used is given in Fig. 3. Rs revealed the solution resistance between the working and reference electrodes, CPE1 was capacitance of corrosion product film, $C P E 2$ was double layer capacitance, $R I$ was the polarization resistance of corrosion product film, and $R 2$ represented the resistance of the double electric double layer.

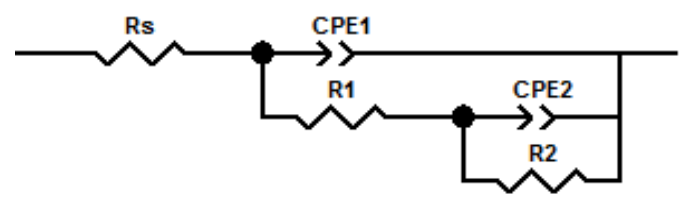

Fig. 3. Electrical equivalent circuits diagrams used to model metal/solution interface, $R s$ : the solution resistance between the working and reference electrodes, CPE1: corrosion product film capacitance, $C P E 2$ : double layer capacitance (due to dispersion effect, $C P E$ was used to represent pure capacitance $\mathrm{C}), R \mathrm{R}$ : the polarization resistance of corrosion product film, $R 2$ : the resistance of the double electric double layer

The electrochemical parameter values obtained are listed in Table 5. As seen in the table, the solution resistance $(R s)$ decreased continually due to the increase of the concentration of $\mathrm{Cl}^{-}$, because the solution conductivity increased with the ion concentration increasing. The results were also revealed that polarization resistance ( $R 1$ and $R 2)$ decreased with the $\mathrm{Cl}^{-}$concentration increasing firstly, and then increased with the concentration of $\mathrm{Cl}^{-}$increasing. When the concentration of $\mathrm{Cl}^{-}$was $2.3 \mathrm{wt} . \%$, the polarization resistance presented the smallest value, revealed that the corrosion of HAl77-2 was the most serious. The results were in a good agreement with the potentiodynamic polarization experiment. By comparison, the charge transfer resistance $R 2$ and film resistance $R 1, R 2$ was far bigger than $R 1$. Thus, the charge transfer process was the main rate control step for corrosion of HAl77-2.

On the other hand, when increasing the concentration of $\mathrm{Cl}^{-}$, double layer capacitance values tend to increase first, and then decrease reaching the highest values when the concentration of $\mathrm{Cl}^{-}$was 2.3 wt. $\%$, revealing the highest corrosion rate. 
Table 5. EIS parameters of HAl77-2 in artificial seawater with different concentrations of $\mathrm{Cl}^{-}$at $313 \mathrm{~K}$

\begin{tabular}{|c|c|c|c|c|c|c|c|}
\hline$C_{\mathrm{Cl}}, \mathrm{wt} . \%$ & $R s, \Omega \cdot \mathrm{cm}^{2}$ & $C P E 1, \mathrm{~F} \cdot \mathrm{cm}^{-2} \mathrm{~S}^{(\mathrm{n}-1)}$ & $\mathrm{n} 1$ & $R 1, \Omega \cdot \mathrm{cm}^{2}$ & $C P E 2, \mu F \cdot \mathrm{cm}^{-2} S^{(n-1)}$ & $\mathrm{n} 2$ & $R 2, \Omega \cdot \mathrm{cm}^{2}$ \\
\hline 1.5 & 3.197 & 5.30 & 0.875 & 2.893 & 188.57 & 0.694 & 3992 \\
\hline 1.9 & 2.724 & 3.41 & 0.807 & 2.561 & 214.44 & 0.703 & 2898 \\
\hline 2.3 & 2.464 & 5.97 & 0.804 & 2.141 & 318.51 & 0.665 & 2200 \\
\hline 2.7 & 2.345 & 3.24 & 0.842 & 4.235 & 136.22 & 0.718 & 2613 \\
\hline
\end{tabular}

\subsection{Effect of temperature on corrosion behavior of HAl77-2}

Effect of temperature on corrosion behavior of HAl772 was also investigate during electrochemical experiments, and the tests was performed in the artificial seawater with the concentration of $\mathrm{Cl}^{-}$as $1.9 \mathrm{wt} . \%$. The $\mathrm{OCP}$ value of HA177-2 in artificial seawater at different temperatures is presented in Table 6.

Table 6 The OCP value of HAl77-2 at different temperatures in artificial seawater with $1.9 \mathrm{wt} . \%$ chloride ion

\begin{tabular}{|c|c|c|c|c|}
\hline$T, \mathrm{~K}$ & 298 & 313 & 328 & 343 \\
\hline$O C P, \mathrm{~V}$ & -0.197 & -0.237 & -0.263 & -0.272 \\
\hline
\end{tabular}

As presented in the figure, the OCP value behaved a trend of continuous electronegative shift with the temperature increasing, indicating corrosion tendency of HAl77-2 in artificial seawater increased with the rise of temperature. Meanwhile, when the temperature increased from $328 \mathrm{~K}$ to $343 \mathrm{~K}$, the negative shift level of OCP value was alleviating slightly, indicating when the temperature rises to high value, effect of temperature on corrosion behavior of HAl77-2 will be weakening.

Fig. 4 shows the polarization curves of HAl77-2 in artificial seawater at different temperatures. The figure showed that anodic passivation phenomenon appeared in the anodic process, and the cathode process had obvious concentration polarization. Hence, cathode process of metal corrosion was controlled by the diffusion of dissolved oxygen in solution, while its affect effect was mitigated with temperature increasing.

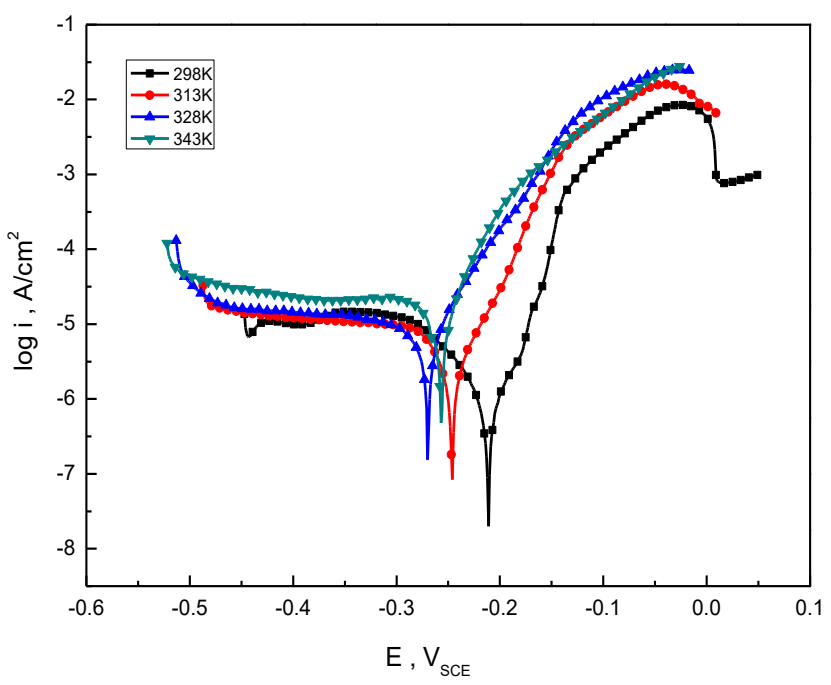

Fig. 4. The polarization curves of HAl77-2 at different temperatures in artificial seawater with 1.9 wt. $\% \mathrm{Cl}^{-}$

Table 7 presents the parameters obtained from potentiodynamic polarization curves for HAl77-2 in artificial seawater at different temperatures.

Table 7. Parameters from potentiodynamic polarization curves of HA177-2 at different temperatures in artificial seawater with 1.9 wt.\% chloride ion

\begin{tabular}{|c|c|c|c|c|}
\hline$T, K$ & $b_{a}, \mathrm{mV} \cdot \mathrm{sec}^{-1}$ & $b_{c}, \mathrm{mV} \cdot \mathrm{sec}^{-1}$ & $i_{\text {corr }}, \mathrm{A} \cdot \mathrm{cm}^{-2}$ & $E_{\text {corr }}, \mathrm{V}$ \\
\hline 298 & 30.473 & -120.14 & $2.800 \times 10^{-6}$ & -0.209 \\
\hline 313 & 35.804 & -199.61 & $4.698 \times 10^{-6}$ & -0.239 \\
\hline 328 & 47.523 & -245.24 & $6.629 \times 10^{-6}$ & -0.268 \\
\hline 343 & 45.262 & -279.23 & $1.372 \times 10^{-5}$ & -0.263 \\
\hline
\end{tabular}

It can be concluded by the table that corrosion potential $\left(E_{c o r r}\right)$ of HAl77-2 shifted to electronegative direction constantly and the corrosion current $\left(i_{\text {corr }}\right)$ increasing with the increase of temperature. It revealed corrosion of HAl772 increased with the rise of temperature. Anodic Tafel slope $\left(b_{a}\right)$ and cathodic Tafel slope $\left(b_{c}\right)$ showed that both anodic and cathodic reaction are affected by the temperature. The values of $b_{c}$ and $b_{c}$ are increasing as the temperature increasing, meanwhile, the change in values $b_{c}$ is more than $b_{a}$.

EIS response of HAl77-2 in artificial seawater at different temperatures is presented in Fig. 5, and the curve feature was similar to Fig. 2. The equivalent circuit in Fig. 3 was used to fit the curve and get the parameters were presented in Table 8 .

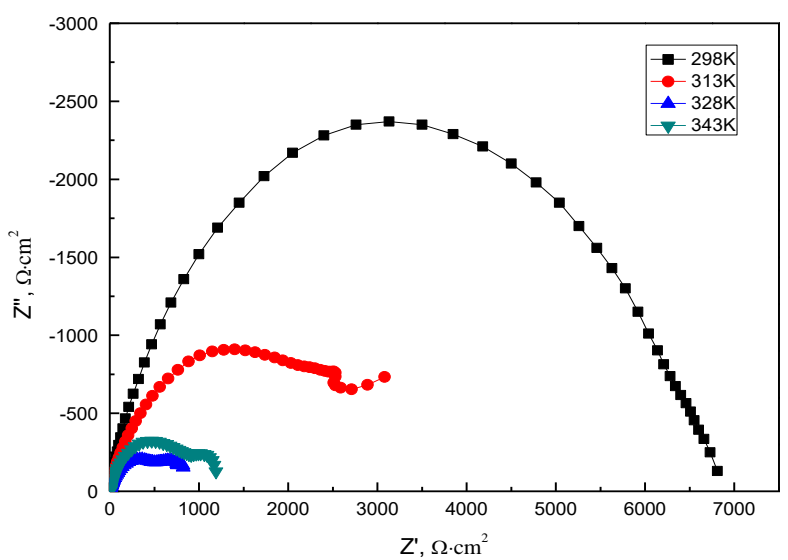

Fig. 5. EIS response of HAl77-2 at different temperatures in artificial seawater with 1.9 wt. \% chloride ion

As seen in the table, both solution resistance $(R s)$ and the resistance of the double electric double layer $(R 2)$ decreased continuously with the increase of temperature, and double layer capacitance values increased with the temperature, illustrated that corrosion reaction resistance of HA177-2 decreases with the temperature rising, and corrosion become more serious at the higher temperature. This conclusion was consistent with the results obtained from the potentiodynamic polarization method. 
Table 8. EIS parameters of HAl77-2 at different temperatures in artificial seawater with $1.9 w t$. \% chloride ion

\begin{tabular}{|c|c|c|c|c|c|c|c|}
\hline$T, \mathrm{~K}$ & $R S, \Omega^{\mathrm{x}} \mathrm{cm}^{2}$ & $\begin{array}{c}C P E 1, \\
\mu \mathrm{F} \cdot \mathrm{cm}^{-2} \mathrm{~S}^{(\mathrm{n}-1)}\end{array}$ & $n 1$ & $R 1, \Omega \cdot \mathrm{cm}^{2}$ & $\begin{array}{c}C P E 2, \\
\mu \mathrm{F} \cdot \mathrm{cm}^{-2} \mathrm{~S}^{(\mathrm{n}-1)}\end{array}$ & $n 2$ & $R 2, \Omega \cdot \mathrm{cm}^{2}$ \\
\hline 298 & 2.956 & 3.11 & 0.861 & 7.705 & 137.72 & 0.744 & 6676 \\
\hline 313 & 2.724 & 3.41 & 0.807 & 2.561 & 214.44 & 0.703 & 2898 \\
\hline 328 & 2.485 & 8.69 & 0.844 & 5.400 & 245.95 & 0.644 & 651.7 \\
\hline 343 & 2.188 & 3.81 & 0.913 & 2.844 & 256.98 & 0.674 & 645.3 \\
\hline
\end{tabular}
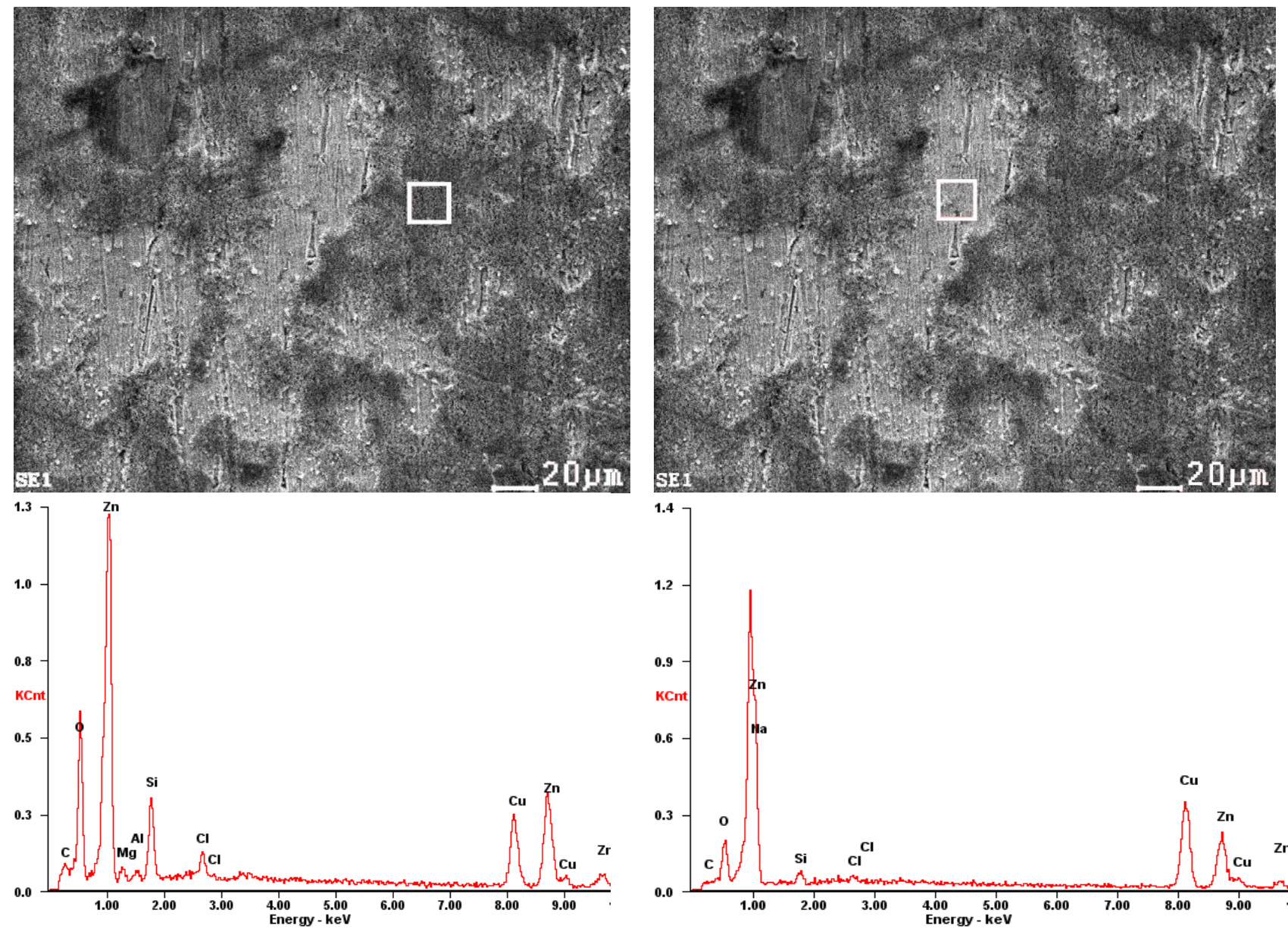

a

$\mathrm{b}$

\begin{tabular}{|c|c|c|c|c|c|}
\hline \multicolumn{2}{|c|}{ Region (a) } & \multicolumn{3}{c|}{ Region (b) } \\
\hline Element & wt.\% & at.\% & Element & wt.\% & at.\% \\
\hline $\mathrm{C}$ & 8.69 & 23.04 & $\mathrm{C}$ & 2.30 & 8.98 \\
\hline $\mathrm{O}$ & 17.26 & 34.34 & $\mathrm{O}$ & 8.01 & 23.49 \\
\hline $\mathrm{Mg}$ & 1.35 & 1.77 & $\mathrm{Si}$ & 1.65 & 2.75 \\
\hline $\mathrm{Al}$ & 0.83 & 0.97 & $\mathrm{Cl}$ & 0.94 & 1.25 \\
\hline $\mathrm{Si}$ & 5.96 & 6.75 & $\mathrm{Cu}$ & 50.01 & 36.92 \\
\hline $\mathrm{Cl}$ & 1.66 & 1.49 & $\mathrm{Zn}$ & 37.09 & 26.62 \\
\hline $\mathrm{Cu}$ & 24.72 & 12.38 & & & \\
\hline $\mathrm{Zn}$ & 39.54 & 19.25 & & & \\
\hline
\end{tabular}

Fig. 6. SEM and EDX analysis for HAl77-2 after immersion in artificial seawater 1.9 wt. $\%$ chloride ion at $313 \mathrm{~K}$ for 30 days

\subsection{SEM and EDX analysis}

Fig. 6 presents the SEM and EDX analysis results for HAl77-2 after immersion in artificial seawater 1.9 wt.\% chloride ion at $313 \mathrm{~K}$ with for 30 days. The surface morphology showed that the character of localized corrosion appeared remarkably on the surface of HAl77-2.
Several metal components, such as $\mathrm{Al}, \mathrm{Zn}, \mathrm{Mg}, \mathrm{Cu}$, etc., were contained in HAl77-2. Thus, when aluminum brass was immersing in artificial seawater, selective localized corrosion occurred on the surface of aluminum brass, and reactive metal components, such as $\mathrm{Zn}$ and $\mathrm{Al}$, preferentially corroded. It was easily to found zinc and aluminum corroded in priority on the surface of HAl77-2 by 
contrasting the element from region (a) and (b).

\section{Conclusions}

1. Corrosion of HAl77-2 in the desalination artificial seawater depended on chloride ion concentrations. Corrosion rate of HAl77-2 initial increased and subsequently decreased with the chloride ion concentrations increasing, and the maximum appeared when the concentration of $\mathrm{Cl}^{-}$reached $2.3 \mathrm{wt} . \%$. At this time, the anode corrosion behaved the most serious.

2. Corrosion potential $\left(E_{\text {corr }}\right)$ of HAl77-2 shifted to electronegative direction constantly and the corrosion current $\left(i_{c o r r}\right)$ increased with the increase of temperature. Corrosion of HAl77-2 increased with temperature enhancing.

3. Selective localized corrosion appeared remarkably, and zinc and aluminum corroded in priority on the surface of HAl77-2.

\section{Acknowledgments}

This work is supported by National Natural Science Foundation of China (NSFC, 41206063), Shandong Provincial Natural Science Foundation, China (ZR2017MEM015), and the Fundamental Research Funds for the Central Universities of China (14CX02201A, 15CX05023A). The financial support from the China Scholarship Council (CSC) is also grateful acknowledged.

\section{REFERENCES}

1. Sharon, H., Reddy, K.S. A Review of Solar Energy Driven Desalination Technologies Renewable \& Sustainable Energy Reviews 41 (C) 2015: pp. 1080-1118. https://doi.org/10.1016/j.rser.2014.09.002

2. Miller, S., Shemer, H., Semiat, R. Energy and Environmental Issues in Desalination Desalination 366 2015: pp. $2-8$.

https://doi.org/10.1016/j.desal.2014.11.034

3. Kalogirou, S.A. Seawater Desalination Using Renewable Energy Sources Progress in Energy \& Combustion Science $31(3) \quad$ 2005: pp. 242-281. https://doi.org/10.1016/j.pecs.2005.03.001

4. Roberts, D.A., Johnston, E.L., Knott, N.A. Impacts of Desalination Plant Discharges on the Marine Environment: A Critical Review of Published Studies Water Research 44 (18) 2010: pp. 5117-5128. https://doi.org/10.1016/j.watres.2010.04.036

5. Ali, M.T., Fath, H.E.S., Armstrong, P.R. A Comprehensive Techno-Economical Review of Indirect Solar Desalination Renewable \& Sustainable Energy Reviews 15 (8) 2011: pp. $4187-4199$. https://doi.org/10.1016/j.rser.2011.05.012

6. Subramani, A., Badruzzaman, M., Oppenheimer, J., Jacangelo, J.G. Energy Minimization Strategies and Renewable Energy Utilization for Desalination: A Review
Water Research 45 (5) 2011: pp. 1907-1920.

https://doi.org/10.1016/j.watres.2010.12.032

7. Eltawil, M.A., Zhao, Z., Yuan, L. A Review of Renewable Energy Technologies Integrated with Desalination Systems Renewable \& Sustainable Energy Reviews 13 (9) 2009: pp. $2245-2262$.

https://doi.org/10.1016/j.rser.2009.06.011

8. Chaibi, M.T. An Overview of Solar Desalination for Domestic and Agriculture Water Needs in Remote Arid Areas Desalination 127 (127) 2000: pp. 119-133. https://doi.org/10.1016/S0011-9164(99)00197-6

9. García-Rodríguez, L., Palmero-Marrero, A.I., GómezCamacho, C. Comparison of Solar Thermal Technologies for Applications in Seawater Desalination Desalination 142 (142) 2002: pp. 135-142. https://doi.org/10.1016/S0011-9164(01)00432-5

10. Alzafin, Y.A, Mourad, A.H.I., Zour, M.A., Abuzeid, O.A. Stress Corrosion Cracking of Ni-Resist Ductile Iron Used in Manufacturing Brine Circulating Pumps of Desalination Plants Engineering Failure Analysis 16 (3) 2009: pp. 733-739. https://doi.org/10.1016/j.engfailanal.2008.06.013

11. Shannon, M.A., Bohn, P.W., Elimelech, M., Georgiadis, J.G., Marinas, B.J., Mayes, A.M. Science and Technology for Water Purification in the Coming Decades Nature 452 2008: pp. 301-310. https://doi.org/10.1038/nature06599

12. Pearce, M., Brennan, F. Novel Findings in Desalination Desalination $360(11) \quad 2015$ : pp. 13-18. https://doi.org/10.1016/j.desal.2014.12.020

13. Yan, M., Sun, C., Dong, J., Xu, J., Ke, W. Electrochemical Investigation on Steel Corrosion in Iron-rich Clay Corrosion Science 97 2015: pp. 62-73. https://doi.org/10.1016/j.corsci.2015.04.013

14. Kuznetsov, V., Maljusch, A., $\quad$ Souto, R.M., Bandarenka, A.S., Schuhmann, W. Characterisation of Localised Corrosion Processes Using Scanning Electrochemical Impedance Microscopy Electrochemistry Communications 44 (7) 2014: pp. 38-41. https://doi.org/10.1016/j.elecom.2014.04.011

15. Pickering, H.W., Frankenthal, R.P. On the Mechanism of Localized Corrosion of Iron and Stainless

Steel Electrochemical Society $119(10)$ 1972: pp. $1297-1304$.

16. Wexler, S.B.D., Galvele, J.R. Anodic Behavior of Aluminum Straining and a Mechanism for Pitting Journal of the Electrochemical Society $121(10)$ 1974: pp. $1271-1276$.

17. Astarita, A., Curioni, M., Squillace, A., Zhou, X., Bellucci, F., Thompson, G.E., Beamish, K.A. Corrosion Behaviour of Stainless Steel-Titanium Alloy Linear Friction Welded Joints: Galvanic Coupling Materials \& Corrosion $66(2) \quad$ 2015: pp. 111-117. https://doi.org/10.1002/maco.201307476 